\section{$\rightarrow$ \\ Solid-cystic papillary epithelial neoplasm of the pancreas. A diagnostic and therapeutic challenge}

Cystic neoplasms of the pancreas are rare tumors with particular pathological characteristics. These tumors are usually big, full of mucinous secretion, and multilocular at times. Microscopically, cysts are made up of an epithelial column (cystadenomas) or a combination of epithelial column and atypical epithelial cells (cystadenocarcinomas). These carcinomas are usually localized, and $50 \%$ may be cured with surgery alone. Other rare tumors $(<1 \%)$ of the exocrine pancreas include acinar cell carcinoma, sarcoma, and lymphoma.

Among cystic pancreatic tumors, the solid-cystic papillary epithelial neoplasm is a rare tumor predominantly affecting young women, and may be mistaken for other pancreatic tumors when strict diagnostic and therapeutic criteria are not considered (1-4).

As a result of the increasingly improved and common imaging techniques this nosologic condition is now being identified with a higher frequency, but descriptions are limited to only a few case reports, usually in units specifically devoted to pancreatic tumor management (5-7). It was initially described by Frantz in 1959 (1), and has received a wide range of designations: cystic-papillary neoplasm, papillary neoplasm, cystic papillary epithelial neoplasm, solid-cystic acinar tumor, Frantz's tumor, and solid-cystic papillary tumor of the pancreas. It is usually designated as solid papillary epithelial neoplasm of the pancreas (SPENP), which best reflects both its histological characteristics and epithelial nature (8-10).

Among neoplasms of the exocrine pancreas, SPENP represents $1 \%$ of such tumors, with a female:male ratio of $13: 1$, and a mean age of 27 years $(11,12)$. It is usually asymptomatic, and hence its diagnosis is usually incidental during diagnostic tests or surgical explorations for other reasons. When symptomatic, complaints are nonspecific for a number of years, with diffuse pain in the epigastrium or left hypochondrium, sometimes in association with abdominal trauma, which leads to some sort of radiographic examination for diagnosis. Virtually all patients will have pain at some time during the course of disease, which may on occasion subside after food ingestion, thus mimicking peptic ulcer disease. Pain radiation to the back is an exceptional occurrence, and severe pain often suggests local or splanchnic nerve infiltration, at times considered a sign of nonresectability.

An abdominal mass may sometimes be palpated in the upper abdomen, and bile duct compression is very rare, occurring only when the tumor is located at the head of the pancreas, a site that is otherwise much less common than the body or tail (60$70 \%$ of cases reported).

The initial method for diagnosis is ultrasounds, which reveals a well-delimited solid-cystic mass. CT defines these tumors as big, well-delimited growths with a thick capsule and a hyperdense cystic component showing bleeding areas that delimit cystic cavities with solid areas and calcifications (13-15). MRI provides information similar 
to that of CT. Angio-CT may be useful to characterize these huge pancreatic masses, and reveals an avascular or hypovascular pancreatic mass. Usually a CT-based diagnosis may suffice for a young woman with a big, well-delimited, encapsulated pancreatic mass with calcification areas and bleeding foci resembling cyst formation.

Improved imaging techniques provide a more accurate extension diagnosis, which implies a higher precision in tumor resectability assessment. A most common cause of undetected nonresectability when using CT is the tumor's vascular infiltration; the sensitivity of helical CT for a successful assessment of such vascular infiltration is 60$89 \%$. The splendid images provided by volumetric angio-CT facilitate diagnosis, and demonstrate the anatomic relation to the vascular tree, thus allowing a more appropriate planning for surgery. Much less valuable than CT are upper gastrointestinal tract contrast radiographic studies, which are commonly unnecessary if one considers that most patients will undergo endoscopy at ERCP. Magnetic resonance imaging (MRI) provides no relevant data in the pancreatic area. MRI may possibly replace CT some time in the future, but the latter is currently the procedure of choice. In rare biliary involvement cases endoscopic retrograde cholangio-pancreatography (ERCP) continues to be a valuable diagnostic tool for the identification of obstructed bile and pancreatic ducts. FNAP demonstrates a highly cellular smear with epithelial cells that may be isolated or clustered in small sheet-like or papillary structures, and display a round or ovoid nucleus, differentiation, intracytoplasmic inclusions, eosinophilic cytoplasm, fine chromatin, commonly clefts with pleomorphisms, hyperchromasia and mitotic activity; the absence of mucus-secreting columnar cells, abundant extracellular mucus, and cell atypia help distinguish solid-cystic papillary neoplasm of the pancreas from mucinous cystic tumors, and mucinous cystadenocarcinomas. Histological and cytologica findings such as atypical aneuploid DNA, and elevated S-phase fraction are usually associated with malignant, metastatic tumors (16).

Phenotypically, solid-cystic papillary neoplasm of the pancreas (SCPNP) is a large-diameter (average $9-11 \mathrm{~cm}$ ) tumor that is most commonly found in the body-tail area; it is well delimited, and has solid, cystic and papillary areas with or without bleeding or necrosis points. It usually displaces but does not invade adjacent structures (17-19). The presence of large necrosis and bleeding areas may lead to mistake these tumors for pancreas pseudocysts. Patient history and the above-mentioned characteristics should rather suggest a diagnosis of SCPNP. Differential diagnosis should point to other solid and cystic pancreatic lesions, including inflammatory pseudocysts, mucinous cystic tumors, mucus-secreting tumors, microcystic adenomas, islet cell tumors, acinar cell carcinoma, cystadenocarcinomas, pancreatoblastoma, and vascular tumors such as hemangioma, lymphangioma, and angiosarcoma. Age at onset, gender, and characteristic clinical course help in its differentiation.

Histogenesis is unknown, and many hypotheses have been suggested. We currently agree that SCPNP originates in a pluripotential epithelial stem cell from small pancreatic ducts with exocrine ductal differentiation. Given its prevalence in young adolescent females, both estrogen receptors (ERs) and progesterone receptors (PRs) have been investigated, and elevated PR levels have been found in these tumors in the absence of ERs; thus, these tumors may increase their volume during the reproductive period, and the finding of necrosis and bleeding is associated with a decrease in progesterone levels.

Complications stemming from these tumors include intracystic bleeding (fatal at times), pseudocyst formation, and death from a coagulopathy secondary to persistent bleeding or from cholangitis and septic shock. Should malignization occur, metastases develop in the liver, and in regional, mesenteric, omental, and peritoneal 
lymph nodes. In patients with local or distant (liver, peritoneum) recurrence, longterm survival is better than for pancreas adenocarcinoma (20).

No serum marker suggests this diagnosis, as CEA, CA 19.9, and alpha-fetoprotein are normal. Genetic studies have shown no p53 mutations directly involved in SCPNP oncogenesis. Translocations between chromosomes 13 and 17 have been identified, and K-ras oncogene mutations have been found in malignant samples (21-23).

Once a diagnosis has been reached resectability is then assessed for seemingly localized tumors (24-27). Surgery is the only valid option with proven effectiveness and a high long-term survival rate even in rare malignant cases. Complete resection with tumor-free margins is not surprisingly the option of choice, and may include radical procedures (cephalic duodenopancreatectomy, partial/body-tail pancreatectomy). The effectiveness of chemotherapy and radiotherapy for rare malignant tumors is unknown, but radiosensitive cases and effective therapies with cisplatin, 5fluoruracil, and VP16 have been reported. Operative mortality for cephalic duodenopancreatectomy in highly experienced centers is lower than $3 \%(28,29)$.

$\mathrm{CT}$ plays an important role in the assessment of upper mesenteric vessels and the celiac trunk. If these are not involved an angio-CT of the portal vein may be obtained, and its resection could be considered. For clearly nonresectable tumors or in the presence of metastatic disease histologic confrmation is required. Angio-CT is used on the one hand to establish the presence of abnormal vascularization, including a right hepatic artery that is a branch of the upper mesenteric artery, and on the other hand to determine nonresectability based on the infiltration of the upper mesenteric artery or, more rarely, hepatic arteries or the celiac trunk. When CT reveals a complete infiltration of the upper mesenteric arteries, common hepatic artery, or celiac trunk, resection is formally contraindicated.

If the tumor is considered nonresectable or metastatic disease is identified histological confirmation is required using fine-needle aspiration puncture (FNAP) to collect pancreatic or liver metastasis biopsy samples.

Surgeons must intraoperatively assess the various arterial and venous vascular structures, and once the upper mesenteric artery, hepatic artery, and portal vein have been seen to be minimally compromised or infiltration-free, a decision to carry on with resection is made.

The order of dissection to obtain the surgical piece is a matter of personal preferences, and is conditioned by the tumor's large volume. A mobilization of the third and fourth duodenal portions, Treitz's ligament, and first jejunal loop is sometimes required early during the procedure and before proceeding with gastric dissection. Pylorus preservation is a widely supported technique nowadays (30). It was first introduced by Traverso and Longmire in 1978, and its goal is to preserve the pylorus, which entails fewer digestive disturbances (31-34).

Body-tail pancreatectomy (distal pancreatectomy), including splenectomy, would be indicated for tumors located in the gland's tail.

So-called "extended resections" for exceptional cases with portal invasion and extended lymphadenectomy $(35,36)$, or "regional pancreatectomy" as described by Fortner in 1973, have undergone further development and been seriously criticized -operative morbidity and mortality are high, and survival has not strikingly increased $(37,38)$. Morbidity and mortality with this sort of surgery have gradually decreased. Cure following successful surgery occurs in $97 \%$ of patients. Long-term mortality is attributed to rare cases of malignant disease with metastases.

In this issue of the Spanish Journal of Gastroenterology, Frago et al. present their experience with the solid pseudopapillary tumor of the pancreas, clinical man- 
ifestations, diagnostic difficulties, its differentiation from neuroendocrine tumors, and therapy problems (39).

\author{
M. Hidalgo Pascual and E. Ferrero Herrero \\ Service of General and Digestive Surgery " B". \\ University Hospital 12 de Octubre. Madrid, Spain
}

\title{
REFERENCES
}

1. Frantz VK. Tumors of the pancreas. In: Atlas of Tumor Pathology, 1st series, fascicle 27-28. Washington, DC: US Armed Forces Institute of Pathology; 1959. p. 32-3.

2. Petrakis I, Vrachassotakis N, Kogerakis N, Hatzidakis A, Zoras O, Chalkiakis G. Solid pseudopapillary neoplasm of the pancreas: Report of a case after a 10-year follow-up and review of the literature. Pancreatology 2001; 1: 123-8.

3. Minz S, Sharma HP, Kumar P, Nirala KP, Shrivastava SK, Khandewal C. Solid-cystic papillary tumour of pancreas. Indian Journal of Pathol Microbiol 2001; 44: 463-4.

4. Pezzi CM, Schuerch C, Erlandson RA, Deitrick J. Papillary-cystic neoplasm of the pancreas. J Surg Oncol 1988; 37: 278-85.

5. Rebhandl W, Felberbauer FX, Puig S, et al. Solid-pseudopapillary tumor of the pancreas (Frantz tumor) in children: Report of four cases and review of the literature. J Surg Oncol 2001; 76: 289-96.

6. Ogawa T, Isagi S, Okamura K, et al. A case of radical resection for solid cystic tumor of the pancreas with widespread metastases in the liver and greater omentum. Am J Gastroenterol 1993; 88: 1436-9.

7. Hurtado AH, Cortés ET. Tumores quísticos. En: Herrera M, Campuzano M, Uscanga L. Páncreas. $2^{\mathrm{a}}$ ed. México: McGraw-Hill; 2000: 421.

8. Burges O, Botella E, Navarro S, Peydro-Olaya A, Llombart-Bosch A. Tumor papilar sólido quístico del páncreas: estudio clinicopatológico de un caso y revisión de la literatura. Rev Esp Patol 1998: 31: 261-7.

9. Kissane JM. Pancreatoblastoma and solid and cystic papillary tumor: Two tumors related to pancreatic ontogeny. Sem Diagn Pathol 1994; 11: 152-64.

10. Mao C, Guvendi M, Domenico DR, et al. Papillary cystic and solid tumors of the pancreas: A pancreatic embryonic tumor? Studies of three cases and cumulative review of the world's literature. Surgery 1995; 118: 821-8

11. Lam KY, Lo CY, Fan ST. Pancreatic solid-cystic-papillary tumor: Clinico-pathologic features in eight patients from Hong Kong and review of the literature. World J Surg 1999; 23: 1045-50.

12. Schwartz DC, Campos MA: A women with recurrent abdominal pain. Am J Med Sci 2001; 321: 352-4

13. Procacci C, Biasiutti C, Carbognin G, et al. Characterization of cystic tumors of the pancreas: CT accuracy. J Comput Assist Tomogr 1999; 23: 906-12.

14. Buetow PC, Buck JL, Pantongrag-Brown L, Beck KG, Ros PR, Adair CF: Solid and papillary epithelial neoplasm of the pancreas: Imaging-pathologic correlation in 56 cases. Radiology 1996; 199: 707-11.

15. Dong PR, Lu DSK, Degregario F, et al. Solid and papillary neoplasm of the pancreas. Radiological-pathological study of five cases and review of literature. Clin Radiol 1996; 51: 702-5.

16. Crawford BE 2nd. Solid and papillary epithelial neoplasm of the pancreas, Diagnosis by cytology. South Med J 1998; 91: 973-7.

17. Tornoczky T, Kalman E, Jakso P, et al. Solid and papillary epithelial neoplasm arising in heterotopic pancreatic tissue of the mesocolon. J Clin Pathol 2001; 54: 241-5.

18. Pettinato G, Manivel JC, Ravetto C, et al. Papillary cystic tumor of the pancreas: A clinicopathologic study of 20 cases, with cytologic, immunohistochemical, ultrastructural and flow cytometric observations and a review of the literature. Am J Clin Pathol 1992; 98: 478-88.

19. Balercia G, Zamboni G, Bogina G, Mariuzzi GM. Solid-cystic tumor of the pancreas. An extensive ultrastructural study of fourteen cases. J Submicrosc Cytol Pathol 1995; 27: 331-40.

20. Madan AK, Weldon ChB, Long WP, Johnson D, Raafat AML. Solid and papillary epithelial neoplasm of the pancreas. J Surg Oncol 2004; 85: 193-8.

21. Grant LD, Lauwers GY, Meloni AM, et al. Unbalanced chromosomal translocation, der(17)t(13;17) (q14;p11) in a solid and cystic papillary epithelial neoplasm of the pancreas. Am J Surg Pathol 1996; 20: 339-45.

22. Bartsch D, Bastian D, Barth P, et al. K-ras oncogene mutations indicate malignancy in cystic tumors of the pancreas. Ann Surg1998; 228: 79-86.

23. Flejou JF, Boulange B, Bernades P, et al. p53 protein expression and DNA ploidy in cystic tumors of the pancreas. Pancreas 1996; 13: 247-52.

24. Yoon DY, Hines OJ, Bilchik AJ, Lewin K, Cortina G, Reber HA. Solid and papillary epithelial neoplasms of the pancreas: Aggressive resection for cure. Am Surg 2001; 67: 1195-9.

25. Martin RC, Klimstra DS, Brennan MF, Conlon KC. Solid-pseudopapillary tumor of the pancreas: A surgical enigma? Ann Surg Oncol 2002; 9: 35-40.

26. Tang LH, Aydin H, Brennan MF, Klimstra DS. Clinically aggressive solid pseudopapillary tumor of the pancreas. A report of two cases with components of undifferentiated carcinoma and a comparative clinicopathologic analysis of 34 conventional cases. Am J Surg Pathol 2005; 29: 512-9.

27. Casadei R, Santini D, Calculli L, Pezzilli R, Zanini N, Minni F. Pancreatic solid-cystic papillary tumor: clinical features, imaging findings and operative management. JOP. J Pancreas (Online) 2006; 7 (Supl. 1): 134-41. 
28. Cameron JL, Pitt HA,Yeo CJ. One hundred and forty five consecutive pancreaticoduodenectomies without mortality. Ann Surg 1993; 217: 430-8.

29. Yeo CJ, Cameron JL, Sohn TA. Six hundred fifty consecutive pancreatico-duodenectomies in the 1990s: pathology, complications and outcomes. Ann Surg 1997; 226: 248-57.

30. Pellegrini CA, Heck CF, Raper G, Way LW. An analysis of the reduced morbidity and mortality rates after pancreaticoduodenectomy. Arch Surg 1989; 124: 778-81.

31. Yeo CJ, Cameron JL, Lillemoe KD, Sohn TA, Campbell KA, Sauter PK, et al. Pancreaticoduodenectomy with or without distal gastrectomy and extended retroperitoneal lymphadectomy for periampullary adenocarcinoma, part 2: randomized controlled trial evaluating survival, morbidity and mortality. Ann Surgery 236: 355-66; discussion 2002; 366-8.

32. Seiler CA, Wagner M, Schaller B, Sadowski C, Kulli C, Buchler MW. Pylorus preserving or classical Whipple operation in tumors. Initial clinical results of a prospective randomized study. Swiss Surg 2000; 275-82.

33. Wenger FA, Jacobi CA, Haubold K, Zieren HU, Muller JM. Gastrointestinal quality of life after duodenopancreatectomy in pancreatic carcinoma. Preliminary results of a prospective randomized study: pancreatoduodenectomy or pylorus-preserving pancreatoduodenectomy. Chirurg 1999; 70: 1454-9.

34. Makhija R, Tsai P, Kinsnorth A. Pylorus-preserving pancreatoduodenectomy with Billroth I type reconstruccion: a viable option for pancreatic head resection. Hepatobiliary Pancreat Surg 2003; 9: 614-9.

35. Fortner JG. Regional resection of the pancreas. A new surgical approach. Surgery 1973; 73: 307.

36. Aramaki M, Matsumoto T, Etoh T, Himeno Y, Sasaki A, Yada K, et al. Clinical significance of combined páncreas and portal vein resecttion in surgery for pancreatic adenocarcinoma. Hepatogastroenterology 2003; 50: 263-6.

37. Fortner J. Surgical principles for pancreatic cancer: regional total and subtotal pancreatectomy. Cancer 1981; 47: 1712.

38. Pedrazzoli S, DiCarlo V, Dionigi R, Mosca F, Pederzoli P, Pasquali C, et al. Standard vs. extended lymphadenectomy associated with pancreatoduodenectomy in the surgical treatment of adenocarcinoma of the head of the pancreas: a multicenter, prospective, randomized study. Lymphadectomy Study Group. Ann Surg 1998; 228 (4): 508-17.

39. Frago R, Fabregat J, Jorba R, García-Borobia F, Altet J, Serrano MT, et al. Tumor sólido pseudopapilar de páncreas: diagnóstico y tratamiento curativo. Rev Esp Enferm Dig 2006; 98 (11): 809-816. 